OPEN ACCESS

Edited by:

Mingzhi Huang,

South China Normal University, China

Reviewed by:

Pan Yang,

Jinan University, China

Vijay Bhaskar Bojan,

Madurai Kamaraj University, India

*Correspondence:

Chan Lu

chanlu@csu.edu.cn

Shaoyou Lu

lushy23@mail.sysu.edu.cn

Specialty section: This article was submitted to Toxicology, Pollution and the

Environment,

a section of the journal

Frontiers in Environmental Science

Received: 06 December 2021

Accepted: 20 January 2022

Published: 28 February 2022

Citation:

Liu Y, Deng M, Zhang D, Lu C and Lu S (2022) Effect of Preconception, Prenatal and Postnatal Exposure to Ambient Air Pollution on Laryngitis in

Southern Chinese Children.

Front. Environ. Sci. 10:830106. doi: 10.3389/fenvs.2022.830106

\section{Effect of Preconception, Prenatal and Postnatal Exposure to Ambient Air Pollution on Laryngitis in Southern Chinese Children}

\author{
Yanlin Liu' ${ }^{1}$, Miaomiao Deng ${ }^{2}$, Duo Zhang ${ }^{3}$, Chan $\mathrm{Lu}^{2 *}$ and Shaoyou $\mathrm{Lu}^{3 *}$ \\ ${ }^{1}$ School of Transportation and Environment, Shenzhen Institute of Information Technology, Shenzhen, China, ${ }^{2}$ Xiang Ya School of \\ Public Health, Central South University, Changsha, China, ${ }^{3}$ School of Public Health (Shenzhen), Sun Yat-sen University, \\ Guangzhou, China
}

Environmental exposure is considered to be a main triggering factor of laryngitis, a common upper respiratory tract infection, especially in developing countries. However, unclear detrimental air pollutants and lack of understanding on their early-life exposure and laryngitis warrant further investigation. Therefore, a retrospective cohort including 2328 preschool children was conducted during 2015-2016 in Shenzhen, China. We measured ambient air quality of $\mathrm{PM}_{10}, \mathrm{SO}_{2}$ and $\mathrm{NO}_{2}$ in 12 monitoring stations, and obtained childhood laryngitis prevalence and confounding covariates by questionnaire. Multiple logistic regression analysis showed that the lifetime prevalence of childhood laryngitis (12.2\%) was associated with an interquartile range increase in late preconception (adjusted odds ratio: 1.43, 95\% confidence interval: 1.06-1.92), prenatal (1.35, $1.02-1.79)$ and early-postnatal $(1.32,1.11-1.57)$ exposure to $\mathrm{SO}_{2}$. Sensitivity analysis revealed that this relationship appeared more obvious among boys without parental atopy, mold/damp stains, or window condensation. Nevertheless, there was no evidence for the association between early-life $\mathrm{PM}_{10}$ and $\mathrm{NO}_{2}$ exposure and childhood laryngitis. These findings suggest that early-life exposure to $\mathrm{SO}_{2}$ significantly increases risk of childhood laryngitis. Preventive measures need to be implemented to mitigate industrial air pollution.

Keywords: childhood laryngitis, air pollution, early life exposure, pregnancy, retrospective cohort study

\section{INTRODUCTION}

Laryngitis, an acute laryngeal inflammation related to upper respiratory tract infection (URTI), is the most common illness self-diagnosed and treated in daily life (Kenealy 2011; Wood et al., 2014). Antibiotics use is a common practice in acute laryngitis treatment especially in low- and middleincome countries (Harris et al., 2016; Odo et al., 2022). It has been currently not supported to prescribe antibiotics to patients with mild URTI (Harris et al., 2016), because inappropriate antibiotics use may promote inflammation (Knoop et al., 2016) and cause other infections or allergic diseases (Çetinkaya and Turgut 2001). Environmental exposure is recognized as a main risk factor of laryngitis (Brauer et al., 2002), whereas certain environmental factors are still unclear, especially for children.

Increasing evidence has linked air pollution with childhood laryngitis (Chauhan and Johnston, 2003; Coates 2006; Aguilera et al., 2012; Kim et al., 2018). Previous studies have found an relationship between traffic-related air pollution and childhood URTIs (Isabelle et al., 2002; Ghosh et al., 2012; 
Elaina et al., 2013). Typical air pollutants such as particulate matter $<10 \mu \mathrm{m}$ in diameter $\left(\mathrm{PM}_{10}\right)$ and sulfur dioxide $\left(\mathrm{SO}_{2}\right)$ are cited as important factors contributing to the increased sore throat, chronic pharyngitis and other acute respiratory infections (Zhou et al., 2001; Acharya et al., 2015). However, present studies only focus on the association between postnatal exposure to air pollutants and respiratory disease (Gehring et al., 2002; Deng et al., 2015), and studies concerning prenatal and preconception exposure to air pollutants are limited (Jedrychowski et al., 2005). Our recent study suggested that preconception, prenatal and postnatal exposure to air pollutants may lead to childhood allergic diseases and symptoms (Deng et al., 2016). However, whether these stages of early-life exposure to air pollutants have adverse effects on URTI remains unclear, and warrants further investigation.

As the largest developing country in the word, China has undergone rapid urbanization and economic growth during recent decades. Huge amounts of pollutants have been discharged from industrial manufacturing and vehicle exhaust, causing serious air pollution in specific regions from China (Watts 2005; Deng et al., 2015). In recent years, although some traditional air pollutants such as $\mathrm{PM}_{10}$ and $\mathrm{SO}_{2}$ have decreased due to the energy conservation and emissions reduction strategy conducted by the Chinese Government, the overall levels of air pollutants in many cities, especially in those with heavy industries, remain high (Kan et al., 2012; Zhang et al., 2012). Shenzhen, located in the Pearl River Delta, is one of the most developed and urbanized regions in China. The rapid economic development in Shenzhen in recent decades has led to serious air pollution (Lu et al., 2018). According to the Seventh National Census of China, Shenzhen possesses a young population, with an average age of 33 years. Therefore, a large number of kindergarten children in Shenzhen are potentially exposed to ambient air pollutants.

Following up on the China, Children, Homes, Health Study conducted in 2010-2012 in several cities (Zhang et al., 2013; Deng et al., 2015), this retrospective cohort study was carried out in Shenzhen during 2015-2016. We put forward a hypothesis that early-life exposure to air pollutants may promote URTI development in children. Therefore, this study was to investigate the effect of preconception, prenatal and postnatal exposure to air pollutants on childhood laryngitis risk.

\section{MATERIALS AND METHODS}

\section{Study Population and Questionnaires}

The investigation was carried out in Shenzhen during 2015-2016. A total of 4700 questionnaires were distributed to participating children from 30 kindergartens in Shenzhen (Supplementary Figure S1), based on random selection and even distribution in the city. The study obtained approval of the Ethics Committee of Shenzhen Institute of Information Technology, China and the health departments of all kindergartens. The questionnaire was designed in Chinese according to the International Study of Asthma and Allergies in Childhood (Asher et al., 2006) with slight modifications considering the cultural and housing features of China for collecting information about personal health status, such as preterm birth and gestational age, possible chemical exposure at home, as well as family members' lifestyle. The questionnaire was completed by the parents, who were required to return the questionnaire to the kindergartens within 1 week.

A total of 4614 questionnaires were received, and the response rate was $>98 \%$. First, we only included children aged 3-6 years $(n=3266)$ for further analysis. Subsequently, 938 of the 3266 invalid questionnaires were excluded due to missing a lot of information such as children's gender, age, health outcomes, mothers' personal exposure to outdoor air pollutants, as well as other related information. Ultimately, 2328 valid questionnaires were included in the study and underwent further analysis.

\section{Time Windows of Early-Life Exposure to Air Pollutants}

Three time windows of the early-life exposure to air pollutants were defined as: preconception period (being exposed to air pollutants during 1 year and 1 month prior to conception); prenatal period (being exposed to air pollutants throughout pregnancy, which is divided into three trimesters); and postnatal period (being exposed to air pollutants from the first year after birth to the present day).

\section{Air Pollutants and Temperature}

The study focused on three outdoor air pollutants, $\mathrm{SO}_{2}, \mathrm{NO}_{2}$ and $\mathrm{PM}_{10} \cdot \mathrm{SO}_{2}$ represents industrial air pollution, $\mathrm{NO}_{2}$ represents traffic-related air pollution and $\mathrm{PM}_{10}$ represents a complex mixture (Kan et al., 2012). We obtained the averaged concentrations of 24-h $\mathrm{PM}_{10}, \mathrm{SO}_{2}$ and $\mathrm{NO}_{2}$ from 12 municipal environmental monitoring stations in Shenzhen (Supplementary Figure S1) during 2008-2013, covering the periods of maternal preconception, prenatal and postnatal exposure to air pollutants. The levels of air pollutants were measured according to the standard methods regulated by the Ministry of Ecology and Environment of China. $\mathrm{PM}_{10}, \mathrm{SO}_{2}$ and $\mathrm{NO}_{2}$ were assessed via a tapered element oscillating microbalance (TEOM1400, Rupprecht and Patashnick, Albany, NY, United States), ultraviolet fluorescent technique (ML/EC9850, Ecotech, Knoxfield, VIC, Australia) and chemiluminescent technique (ML/EC9841B, Ecotech), respectively. The ambient temperature on an hourly basis was collected from the meteorological monitoring stations (Supplementary Figure S1).

An inverse distance weighted method was used to calculate the personal exposure to $\mathrm{PM}_{10}, \mathrm{SO}_{2}$ and $\mathrm{NO}_{2}$ according to a previous study (Deng et al., 2015). Firstly, the data measured in the 12 municipal environmental monitoring stations closet to kindergartens were taken into account to estimate the daily average concentrations of $\mathrm{PM}_{10}, \mathrm{SO}_{2}$ and $\mathrm{NO}_{2}$ at each kindergarten. Then, we calculated each child's exposure to air pollutants $\left(\mathrm{PM}_{10}, \mathrm{SO}_{2}\right.$ and $\left.\mathrm{NO}_{2}\right)$ and temperature during the three timing windows as the daily average $\mathrm{NO}_{2}$ during the preconception, prenatal and postnatal periods. 


\section{Health Outcomes}

Laryngitis was defined by parents definitively answer the following question from doctors "Has your child ever been diagnosed with laryngitis by a doctor?"

\section{Confounding Covariates}

Information about the potential confounders came from the questionnaire. The analysis in this study mainly confirmed three confounding variables, inclusive of the personal factors such as gender, age, birth season, gestational age, breastfeeding, parental atopy and time to kindergarten and home environmental factors such as passive smoking, paint in the child's room, visible mold/damp stains in the child's room, window condensation at home and raising dogs, as well as socioeconomic status (maternal education level and maternal occupation) (Supplementary Table S1).

\section{Statistical Analysis}

Multiple logistic regression models were constructed to investigate how ambient air pollutants $\left(\mathrm{PM}_{10}, \mathrm{SO}_{2}\right.$ and $\left.\mathrm{NO}_{2}\right)$ affected childhood laryngitis during the preconception, prenatal and postnatal periods, with adjustment for potential confounding covariates. The analysis included $\mathrm{PM}_{10}, \mathrm{SO}_{2}$ and $\mathrm{NO}_{2}$ as the continuous variables, calculating the odds ratio (OR) and $95 \%$ confidence interval $(\mathrm{CI})$ specific to the per-interquartile range (IQR) increase in $\mathrm{PM}_{10}, \mathrm{SO}_{2}$ and $\mathrm{NO}_{2}$. First, a simple univariate analysis was conducted to determine covariates of childhood laryngitis diagnosed by physicians. Subsequently, a singlepollutant model was performed to estimate the adjusted effect of childhood laryngitis by exposure to each air pollutant. Moreover, because these three air pollutants have no internal correlations and represent different exposure sources, we applied a multi-pollutant model to evaluate the adjusted effects by other air pollutants during each time window. Additionally, during the whole pregnancy, a multi-pollutant model together with a multiwindow model were used to adjust the effects of other air pollutants, to ascertain how air pollutants affected childhood laryngitis during a specific trimester. A $p$ value $\leq 0.05$ exhibited statistical significance. SPSS version 22.0 (SPSS Inc., Chicago, IL, United States) was used for all statistical analyses.

\section{RESULTS AND DISCUSSION}

The environmental triggering factors of laryngitis are still unclear, especially in sensitive populations such as children. To our knowledge, this is the first retrospective cohort study to explore preconception, prenatal and postnatal exposure to ambient air pollutants and childhood laryngitis. The results showed that exposure to industrial air pollution $\left(\mathrm{SO}_{2}\right)$ during the late preconception, pregnancy, and early-postnatal periods may increase laryngitis risk among children. Furthermore, this relationship appeared more obvious among boys without parental atopy, mold/damp stains, or window condensation. However, there was no evidence for the relationship between laryngitis and early-life exposure to $\mathrm{PM}_{10}$ and $\mathrm{NO}_{2}$ during any of the considered windows.
TABLE 1 | Statistics of being exposed to outdoor air pollution during preconceptional, prenatal, and postnatal periods among children aged 3-6 years $(n=2,328)$.

\begin{tabular}{|c|c|c|c|c|c|c|}
\hline & Mean & SD & $25 \%$ & $50 \%$ & $75 \%$ & IQR \\
\hline \multicolumn{7}{|c|}{ Preconceptional } \\
\hline \multicolumn{7}{|c|}{1 year before conception } \\
\hline $\mathrm{PM}_{10}$ & 59 & 5 & 55 & 58 & 62 & 7 \\
\hline $\mathrm{SO}_{2}$ & 13 & 2 & 11 & 13 & 14 & 3 \\
\hline $\mathrm{NO}_{2}$ & 44 & 5 & 41 & 43 & 46 & 5 \\
\hline \multicolumn{7}{|c|}{1 month before conception } \\
\hline $\mathrm{PM}_{10}$ & 58 & 20 & 43 & 54 & 71 & 28 \\
\hline $\mathrm{SO}_{2}$ & 12 & 4 & 9 & 11 & 15 & 6 \\
\hline $\mathrm{NO}_{2}$ & 43 & 12 & 35 & 40 & 49 & 14 \\
\hline \multicolumn{7}{|c|}{ Pregnancy } \\
\hline $\mathrm{PM}_{10}$ & 57 & 16 & 44 & 57 & 68 & 24 \\
\hline $\mathrm{SO}_{2}$ & 12 & 3 & 10 & 11 & 14 & 4 \\
\hline $\mathrm{NO}_{2}$ & 43 & 10 & 36 & 41 & 49 & 13 \\
\hline \multicolumn{7}{|c|}{ 2nd trimester } \\
\hline $\mathrm{PM}_{10}$ & 58 & 15 & 46 & 58 & 69 & 23 \\
\hline $\mathrm{SO}_{2}$ & 12 & 3 & 9 & 11 & 14 & 5 \\
\hline $\mathrm{NO}_{2}$ & 44 & 10 & 37 & 41 & 49 & 12 \\
\hline \multicolumn{7}{|c|}{ 3rd trimester } \\
\hline $\mathrm{PM}_{10}$ & 58 & 16 & 45 & 57 & 69 & 24 \\
\hline $\mathrm{SO}_{2}$ & 11 & 3 & 9 & 11 & 14 & 5 \\
\hline $\mathrm{NO}_{2}$ & 44 & 10 & 37 & 41 & 49 & 12 \\
\hline \multicolumn{7}{|c|}{ Entire pregnancy } \\
\hline $\mathrm{PM}_{10}$ & 57 & 7 & 52 & 57 & 62 & 10 \\
\hline $\mathrm{SO}_{2}$ & 12 & 2 & 10 & 12 & 13 & 3 \\
\hline $\mathrm{NO}_{2}$ & 43 & 6 & 40 & 43 & 46 & 6 \\
\hline \multicolumn{7}{|c|}{ Postnatal } \\
\hline \multicolumn{7}{|c|}{ First year } \\
\hline $\mathrm{PM}_{10}$ & 57 & 6 & 53 & 57 & 61 & 8 \\
\hline $\mathrm{SO}_{2}$ & 11 & 2 & 10 & 11 & 12 & 2 \\
\hline $\begin{array}{l}\mathrm{NO}_{2} \\
\text { Past }\end{array}$ & 43 & 6 & 39 & 44 & 46 & 7 \\
\hline $\mathrm{PM}_{10}$ & 51 & 7 & 46 & 50 & 55 & 9 \\
\hline $\mathrm{SO}_{2}$ & 9 & 1 & 8 & 9 & 9 & 1 \\
\hline $\mathrm{NO}_{2}$ & 36 & 5 & 32 & 37 & 39 & 7 \\
\hline \multicolumn{7}{|c|}{ Entire postnatal } \\
\hline $\mathrm{PM}_{10}$ & 57 & 5 & 53 & 55 & 61 & 8 \\
\hline $\mathrm{SO}_{2}$ & 10 & 1 & 9 & 10 & 11 & 2 \\
\hline $\mathrm{NO}_{2}$ & 39 & 5 & 36 & 39 & 43 & 7 \\
\hline
\end{tabular}

$P M_{10}\left(\mu \mathrm{g} / \mathrm{m}^{3}\right)=$ particulate matter $\leq 10 \mu \mathrm{m}$ in aerodynamic, $\mathrm{SO}_{2}\left(\mu \mathrm{g} / \mathrm{m}^{3}\right)=$ sulfur dioxide, $\mathrm{NO}_{2}\left(\mu \mathrm{g} / \mathrm{m}^{3}\right)=$ nitrogen dioxide.

\section{Demographics and Laryngitis Prevalence}

Among the 2328 respondents, 283 (12.2\%) were diagnosed with laryngitis. Supplementary Table $\mathbf{S 1}$ listed the demographics and laryngitis prevalence among children under the stratification of covariates. Children with parental atop and indoor environmental factors including tobacco smoking, mold/damp stains and window condensation, as well as maternal occupation presented with higher prevalence of laryngitis compared to those without parental atopy. However, we found that childhood laryngitis was not associated with gender, age, birth season, gestational age, breast-feeding, time to kindergarten, paint in children's rooms, raising dogs and maternal education level.

\section{Outdoor Air Pollutants Exposure}

Table 1 presents children's exposure to outdoor air pollutants $\mathrm{PM}_{10}, \mathrm{SO}_{2}$ and $\mathrm{NO}_{2}$ within different time windows. The 
TABLE 2 | Odds ratio of laryngitis due to outdoor air pollution exposure during preconception period among children aged 3-6 years $(n=2,328)$.

\begin{tabular}{|c|c|c|c|c|c|}
\hline & \multirow{2}{*}{$\frac{\text { Single-pollutant model }}{\text { Adjusted } \text { OR }^{\mathbf{b}}}$} & \multicolumn{4}{|c|}{ Multi-pollutant model $^{a}$} \\
\hline & & $\mathrm{PM}_{10}+\mathrm{SO}_{2}$ & $\mathrm{PM}_{10}+\mathrm{NO}_{2}$ & $\mathrm{SO}_{2}+\mathrm{NO}_{2}$ & $\begin{array}{c}\mathrm{PM}_{10}+\mathrm{SO}_{2}+ \\
\mathrm{NO}_{2}\end{array}$ \\
\hline \multicolumn{6}{|c|}{1 year before conception } \\
\hline $\mathrm{PM}_{10}$ & $1.04(0.97,1.11)$ & $0.81(0.64,1.01)$ & $1.02(0.88,1.18)$ & - & $0.80(0.62,1.03)$ \\
\hline $\mathrm{SO}_{2}$ & $1.10(0.98,1.23)$ & $1.56(1.06,2.28)^{\star}$ & - & $1.18(0.95,1.46)$ & $1.55(1.06,2.28)^{*}$ \\
\hline $\mathrm{NO}_{2}$ & $1.04(0.97,1.11)$ & - & $1.02(0.88,1.18)$ & $0.95(0.84,1.09)$ & $1.01(0.87,1.17)$ \\
\hline \multicolumn{6}{|c|}{1 month before conception } \\
\hline $\mathrm{PM}_{10}$ & $1.22(0.88,1.68)$ & $0.96(0.65,1.43)$ & $1.15(0.79,1.67)$ & - & $0.96(0.63,1.45)$ \\
\hline $\mathrm{SO}_{2}$ & $1.43(1.06,1.92)^{*}$ & $1.46(1.02,2.09)^{\star}$ & - & $1.43(1.02,2.01)^{\star}$ & $1.45(1.00,2.12)^{*}$ \\
\hline $\mathrm{NO}_{2}$ & $1.16(0.90,1.50)$ & - & $1.10(0.82,1.48)$ & $1.00(0.75,1.34)$ & $1.01(0.74,1.38)$ \\
\hline
\end{tabular}

We estimated the OR $(95 \% \mathrm{Cl})$ specific to per IQR, increase in each air pollutant in different time s.

aMulti-pollutant model: Model adjustment was performed specific to other pollutants during the same time window on the basis of the single adjusted model. ${ }^{*} \mathrm{p} \leq 0.05 .{ }^{* *} \mathrm{p} \leq 0.01$.

${ }^{b}$ Single adjusted model: Model adjustment was performed specific to all the covariates in Table $\mathbf{1}$ as well as the outdoor air temperature during different time window.

TABLE 3 | Odds ratio of laryngitis due to being exposed to outdoor air pollution during pregnancy among children in the age range of 3-6 years $(n=2,328)$.

\section{Single-pollutant \\ model \\ Adjusted OR $^{\mathrm{b}}$}
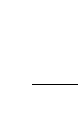

$\mathrm{PM}_{10}+$
$\mathrm{SO}_{2}$

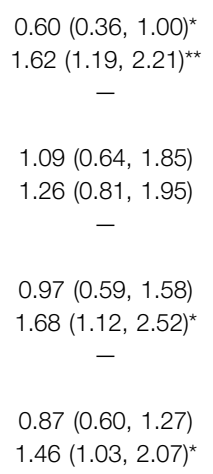

$1.09(0.64,1.85)$

$1.26(0.81,1.95)$

$0.97(0.59,1.58)$

$1.68(1.12,2.52)^{\star}$

$$
-
$$

$0.87(0.60,1.27)$

$1.46(1.03,2.07)^{\star}$

Multi-pollutant model $^{\mathbf{a}}$

$\begin{array}{ccc}\mathrm{PM}_{10}+ & \mathrm{SO}_{2}+ & \mathrm{PM}_{10}+ \\ \mathrm{NO}_{2} & \mathrm{NO}_{2} & \mathrm{SO}_{2}+ \\ & & \mathrm{NO}_{2}\end{array}$

Multi-window model

$$
\text { Adjusted OR }{ }^{\mathrm{c}}
$$

Multi-pollutant + window model Adjusted OR ${ }^{d}$

\section{$0.94(0.58,1.51)$}

$0.97(0.70,1.35)$

$1.54(0.97,2.46)$

$0.69(0.50,0.97)^{\star}$

$1.46(0.94,2.26)$

$-$

$0.84(0.63,1.12)$

$1.13(0.84,1.52)$

$-$

$0.85(0.70,1.02)$

\section{$1.42(1.08,1.86)^{*}$}

$0.86(0.64,1.17)$

$-$

$1.42(0.97,2.09)$

$0.74(0.54,1.00)^{*}$

$-$

$1.74(1.21,2.50)^{\star \star}$

$0.84(0.64,1.11)$

$-$
$1.33(1.00,1.77)^{*}$

$0.87(0.73,1.05)$
$0.62(0.35,1.07)$

$1.63(1.19,2.22)^{\star *}$

$0.95(0.69,1.31)$

$1.32(0.76,2.31)$

$1.26(0.80,1.99)$

$0.70(0.50,0.97)^{\star}$

$1.06(0.64,1.76)$

$1.71(1.13,2.58)^{\star}$

$0.84(0.63,1.11)$

$0.91(0.62,1.33)$

$1.40(0.98,2.02)$

$0.88(0.73,1.06)$
$0.90(0.58,1.40)$

$1.38(1.01,1.89)^{*}$

$1.08(0.77,1.52)$

$1.21(0.77,1.90)$

$0.94(0.61,1.46)$

$0.76(0.51,1.13)$

$1.30(0.86,1.96)$

$1.57(1.09,2.26)^{\star}$

$0.99(0.73,1.33)$
$0.89(0.55,1.45)$

$1.42(1.01,2.01)^{\star}$

$1.14(0.78,1.66)$

$1.49(0.92,2.43)$

$1.04(0.65,1.67)$

$0.60(0.38,0.94)^{\star}$

$1.43(0.93,2.22)$

$1.65(1.12,2.42)^{\star}$

$0.89(0.63,1.24)$

We estimated OR (95\% Cl) specific to per IQR, increase in each air pollutant during different time window.

aMulti-pollutant model: Model adjustment was performed specific to the other pollutants in the same time window on the basis of the single adjusted model.

${ }^{b}$ Single adjusted model: Model adjustment was performed specific to all the covariates in Table 1 as well as the outdoor air temperature in different time window.

${ }^{c}$ Multi-window model: Model adjustment was performed specific to the same pollutant in the other time window on the basis of the single adjusted model.

${ }^{d}$ Multi-pollutant + window model: Models adjustment was performed specific to the same pollutant in the other time windows on the basis of the multi-pollutant model. ${ }^{*} \mathrm{p} \leq 0.05$. ${ }^{* *} \mathrm{p} \leq 0.01$.

average level of exposure (mean $\pm \mathrm{SD}$ ) to $\mathrm{PM}_{10}, \mathrm{SO}_{2}$ and $\mathrm{NO}_{2}$ remained unchanged during three periods. However, during the first to the past year in postnatal period, the three outdoor air pollutants decreased slightly from $57 \pm 6,11 \pm 2$ and $43 \pm$ $6 \mu \mathrm{g} / \mathrm{m}^{3}$ to $51 \pm 7,9 \pm 1$ and $36 \pm 5 \mu \mathrm{g} / \mathrm{m}^{3}$, respectively. A smaller IQR was observed for industrial air pollutant $\mathrm{SO}_{2}$ exposure compared to gaseous pollutants $\left(\mathrm{PM}_{10}\right.$ and $\left.\mathrm{NO}_{2}\right)$.

In addition, ambient temperature within different time windows is listed in Supplementary Table S2. Accordingly, different trimesters of pregnancy presented no temperature difference, while the preconception period, entire pregnancy, and postnatal period showed an obvious difference.

\section{Exposure to Industrial Air Pollution and Laryngitis}

We observed a relationship between childhood laryngitis and exposure to $\mathrm{SO}_{2}$ during late preconception and pregnancy (Tables 2, 3). Childhood laryngitis exhibited a significant relationship with preconception $\mathrm{SO}_{2}$ exposure during the 
TABLE 4 | Odds ratio of laryngitis due to exposure to outdoor air pollution within different time windows among children in the age range of $3-6$ years $(n=2,328)$.

\begin{tabular}{|c|c|c|c|c|c|}
\hline & \multirow{2}{*}{$\frac{\text { Single-pollutant model }}{\text { Adjusted OR }}$} & \multicolumn{4}{|c|}{ Multi-pollutant model $^{\mathrm{a}}$} \\
\hline & & $\mathrm{PM}_{10}+\mathrm{SO}_{2}$ & $\mathrm{PM}_{10}+\mathrm{NO}_{2}$ & $\mathrm{SO}_{2}+\mathrm{NO}_{2}$ & $\begin{array}{c}\mathrm{PM}_{10}+\mathrm{SO}_{2}+ \\
\mathrm{NO}_{2}\end{array}$ \\
\hline \multicolumn{6}{|c|}{ First year } \\
\hline $\mathrm{PM}_{10}$ & $1.19(0.96,1.47)$ & $1.00(0.78,1.29)$ & $1.20(0.96,1.50)$ & - & $1.02(0.79,1.32)$ \\
\hline $\mathrm{SO}_{2}$ & $1.32(1.11,1.57)^{\star \star}$ & $1.32(1.08,1.61)^{\star \star}$ & - & $1.33(1.11,1.58)^{\star \star}$ & $1.32(1.08,1.61)^{\star}$ \\
\hline $\mathrm{NO}_{2}$ & $1.00(0.81,1.24)$ & - & $1.05(0.84,1.31)$ & $1.05(0.85,1.30)$ & $1.06(0.85,1.31)$ \\
\hline \multicolumn{6}{|c|}{ Past year } \\
\hline $\mathrm{PM}_{10}$ & $0.94(0.75,1.17)$ & $0.92(0.74,1.15)$ & $0.94(0.75,1.17)$ & - & $0.92(0.74,1.15)$ \\
\hline $\mathrm{SO}_{2}$ & $1.06(0.92,1.23)$ & $1.07(0.93,1.24)$ & - & $1.06(0.92,1.23)$ & $1.07(0.93,1.24)$ \\
\hline $\mathrm{NO}_{2}$ & $0.98(0.76,1.26)$ & - & $0.99(0.76,1.28)$ & $0.98(0.76,1.27)$ & $1.00(0.77,1.30)$ \\
\hline \multicolumn{6}{|c|}{ Entire postnatal } \\
\hline $\mathrm{PM}_{10}$ & $0.94(0.73,1.21)$ & $0.92(0.72,1.18)$ & $0.93(0.72,1.20)$ & - & $0.93(0.72,1.21)$ \\
\hline $\mathrm{SO}_{2}$ & $1.29(0.99,1.69)$ & $1.30(1.00,1.69)^{\star}$ & - & $1.34(1.00,1.78)^{*}$ & $1.33(1.00,1.77)^{\star}$ \\
\hline $\mathrm{NO}_{2}$ & $0.97(0.74,1.27)$ & - & $0.95(0.72,1.26)$ & $1.10(0.81,1.48)$ & $1.08(0.79,1.47)$ \\
\hline
\end{tabular}

We estimated OR $(95 \% \mathrm{Cl})$ specific to per IQR, increase in every air pollutant in different time windows.

a Multi-pollutant model: Model adjustment was performed specific to the other pollutants in the same time window on the basis of the single adjusted model.

${ }^{b}$ Single adjusted model: Model adjustment was performed specific to all the covariates in Table 1 as well as the outdoor air temperature during different time window.

${ }^{c}$ Multi-window model: Model adjustment was performed specific to the same pollutant in the other time window on the basis of the single adjusted model.

${ }^{d}$ Multi-pollutant + window model: Model adjustment was performed specific to the same pollutant in other time windows on the basis of the multi-pollutant model. ${ }^{*} \mathrm{p} \leq 0.05$. ${ }^{* *} \mathrm{p} \leq 0.01$.

TABLE 5 | Odds ratio of laryngitis due to exposure to outdoor $\mathrm{SO}_{2}$ exposure during different time windows stratified by personal factors including child's sex and parental atopy $(n=2,328)$.

\begin{tabular}{|c|c|c|c|c|}
\hline & \multicolumn{2}{|c|}{ Child's sex } & \multicolumn{2}{|c|}{ Parental atopy } \\
\hline & Boys $(n=1,240)$ & Girls $(n=1,088)$ & Yes $(n=301)$ & No $(n=1,916)$ \\
\hline \multicolumn{5}{|l|}{ Preconceptional } \\
\hline 1 year before conception & $1.10(0.94,1.29)$ & $1.14(0.96,1.34)$ & $1.02(0.77,1.35)$ & $1.12(0.99,1.27)$ \\
\hline 1 month before conception & $1.56(1.05,2.32)^{\star}$ & $1.29(0.81,2.06)$ & $0.81(0.34,1.91)$ & $1.52(1.10,2.10)^{\star}$ \\
\hline \multicolumn{5}{|l|}{ Pregnancy } \\
\hline 1st trimester & $1.49(1.03,2.17)^{\star}$ & $1.25(0.86,1.83)$ & $1.35(0.69,2.62)$ & $1.37(1.03,1.83)^{\star}$ \\
\hline 2nd trimester & $1.13(0.67,1.90)$ & $1.56(0.90,2.71)$ & $1.03(0.37,2.83)$ & $1.30(0.87,1.94)$ \\
\hline 3rd trimester & $1.35(0.80,2.27)$ & $1.90(1.17,3.06)^{\star \star}$ & $0.73(0.29,1.87)$ & $1.84(1.25,2.69)^{\star *}$ \\
\hline Entire pregnancy & $1.24(0.83,1.85)$ & $1.47(0.97,2.22)$ & $1.05(0.48,2.32)$ & $1.37(1.01,1.87)^{\star}$ \\
\hline \multicolumn{5}{|l|}{ Postnatal } \\
\hline First year & $1.35(1.06,1.73)^{\star}$ & $1.28(0.99,1.64)$ & $0.98(0.63,1.54)$ & $1.37(1.13,1.66)^{\star \star \star}$ \\
\hline Past year & $0.96(0.77,1.20)$ & $1.19(0.95,1.49)$ & $1.12(0.71,1.76)$ & $1.06(0.90,1.25)$ \\
\hline Entire postnatal & $1.26(0.87,1.83)$ & $1.41(0.94,2.10)$ & $0.93(0.47,1.84)$ & $1.36(1.01,1.83)^{\star}$ \\
\hline
\end{tabular}

We estimated the OR $(95 \% \mathrm{Cl})$ by single adjusted model for per IQR, increase in the $\mathrm{SO}_{2}$ exposure during different time window. Model adjustment considered all the covariates listed in Table 1, together with the outdoor air temperature during different time windows. ${ }^{*} \mathrm{p} \leq 0.05 .{ }^{* *} \mathrm{p} \leq 0.01$. ${ }^{* * *} \mathrm{p} \leq 0.001$.

month before conception (adjusted OR: 1.43 , 95\%CI: $1.06-$ 1.92) (Table 2). This relationship was not observed during the year before conception. In the multipollutant model, we observed significant ORs for exposure to $\mathrm{SO}_{2}$ plus $\mathrm{PM}_{10}$, $\mathrm{NO}_{2}$, and all three during the late preconception period. We found that childhood laryngitis was also significantly associated with prenatal exposure to the industrial air pollutant $\mathrm{SO}_{2}$ (adjusted OR: 1.35, 95\%CI: 1.02-1.79) (Table 3). This correlation was particularly strong during the first and third trimester with an adjusted OR (95\% CI) of $1.37(1.05-1.77)$ and $1.65(1.10-2.34)$, respectively. In the multi-pollutant model, we further observed that all $\mathrm{SO}_{2}$ related co-exposures during the first and third trimesters were associated with higher risk of laryngitis (Table 3). These results were consistently demonstrated that before birth exposure to $\mathrm{SO}_{2}$ may increase laryngitis incidence.
Recent studies have revealed that prenatal exposure to $\mathrm{SO}_{2}$ may cause URTIs such as otitis media (Deng et al., 2017a; Deng et al., 2017b), as observed in our study. We also demonstrated that maternal exposure to ambient air pollution may make preschool children more susceptible to the common cold (Norbäck et al., 2017). Based on the Barker hypothesis, organs experience growth programming that is capable of disrupting development as well as changing gene transcription and expression on the premise of not changing the DNA sequence, thereby creating a phenotype that is more sensitive to air pollution, and leads to enduring susceptibility in later life (Miller and Ho, 2008). Although the preconception and prenatal periods are important, the effect of preconception exposure to the outdoor air pollution on childhood URTIs has never been investigated.

The effect estimates regarding childhood laryngitis specific to per-IQR increase in air pollutants during the postnatal period are 
TABLE 6 | Odds ratio of laryngitis due to being exposed to outdoor $\mathrm{SO}_{2}$ exposure within various time windows stratified by indoor environmental factors that include indoor mold/damp stains as well as window condensation $(n=2,328)$

\begin{tabular}{|c|c|c|c|c|}
\hline & \multicolumn{2}{|c|}{ Mold/damp stains } & \multicolumn{2}{|c|}{ Window condensation } \\
\hline & Yes $(n=888)$ & No $(n=1,393)$ & Yes $(n=218)$ & No $(n=1,744)$ \\
\hline \multicolumn{5}{|l|}{ Preconceptional } \\
\hline 1 year before conception & $1.04(0.89,1.22)$ & $1.15(0.98,1.36)$ & $0.98(0.74,1.31)$ & $1.13(0.99,1.28)$ \\
\hline 1 month before conception & $1.52(0.94,2.48)$ & $1.38(0.93,2.04)$ & $0.39(0.15,1.06)$ & $1.68(1.22,2.31)^{\star \star \star}$ \\
\hline \multicolumn{5}{|l|}{ Pregnancy } \\
\hline 1st trimester & $1.30(0.85,1.99)$ & $1.50(1.07,2.12)^{\star}$ & $0.96(0.38,2.40)$ & $1.46(1.10,1.94)^{\star \star}$ \\
\hline 2nd trimester & $1.00(0.53,1.87)$ & $1.45(0.92,2.31)$ & $1.39(0.47,4.10)$ & $1.30(0.88,1.94)$ \\
\hline 3rd trimester & $1.36(0.79,2.32)$ & $1.94(1.20,3.11)^{\star \star}$ & $2.22(0.79,6.24)$ & $1.50(1.02,2.19)^{\star}$ \\
\hline Entire pregnancy & $1.17(0.74,1.86)$ & $1.48(1.02,2.15)^{\star}$ & $1.21(0.51,2.83)$ & $1.36(1.00,1.85)^{\star}$ \\
\hline \multicolumn{5}{|l|}{ Postnatal } \\
\hline First year & $1.19(0.90,1.56)$ & $1.40(1.11,1.76)^{\star \star}$ & $1.42(0.81,2.51)$ & $1.30(1.08,1.57)^{\star \star}$ \\
\hline Past year & $1.09(0.85,1.39)$ & $1.05(0.85,1.30)$ & $0.95(0.56,1.61)$ & $1.07(0.91,1.25)$ \\
\hline Entire postnatal & $1.06(0.70,1.60)$ & $1.48(1.02,2.15)^{\star}$ & $1.20(0.52,2.74)$ & $1.31(0.98,1.75)$ \\
\hline
\end{tabular}

We estimated $\mathrm{OR}(95 \% \mathrm{Cl})$ by single adjusted model for per IQR, increase in the $\mathrm{SO}_{2}$ exposure during different time window. Models were adjusted for all the covariates in Table 1, and outdoor air temperature during different time window. ${ }^{*} p \leq 0.05$. ${ }^{* *} p \leq 0.01$. ${ }^{* *} p \leq 0.001$.

listed in Table 4. In the single-pollutant model, childhood laryngitis was significantly related to postnatal exposure to the industrial air pollutant $\mathrm{SO}_{2}$ during the first year after adjusting for the covariates with an adjusted OR (95\% CI) of 1.32 (1.11-1.57), but not related to the past year. There was no relationship between laryngitis and exposure to $\mathrm{PM}_{10}$ or traffic-related air pollutant $\mathrm{NO}_{2}$ during any window. We also found significant $\mathrm{ORs}$ for $\mathrm{SO}_{2}$ during the first year in the multipollutant model after adding other pollutants. Thus, the ORs for $\mathrm{SO}_{2}$ exposure during the first year were consistently significant. This study further demonstrated that being exposed to $\mathrm{SO}_{2}$ during the first year after birth could lead to childhood laryngitis. Children's exposure to environmental factors after the first year of birth can easily impair their respiratory and immune systems (Kozyrskyj et al., 2010; Gascon et al., 2015). Mounting evidence suggests the significance of postnatal exposure to ambient air pollution for the later development of childhood respiratory health (DiFranza et al., 2004; Aguilera et al., 2012; Fuentes-Leonarte et al., 2015).

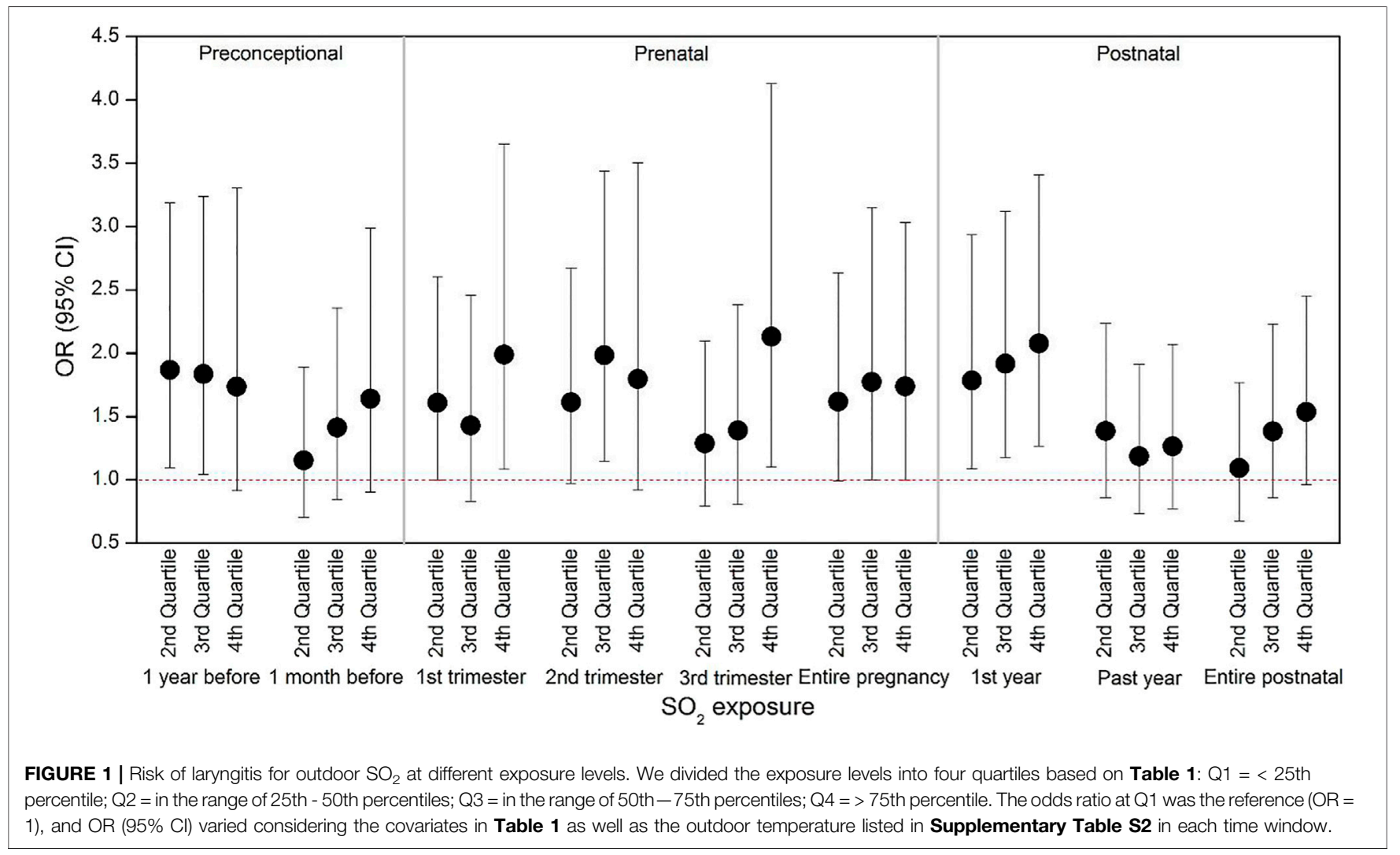


The risk of laryngitis due to air pollution during the preconception, prenatal and postnatal periods stratified by the covariates were listed Tables 5, 6 and Figure 1. Laryngitis risk due to $\mathrm{SO}_{2}$ exposure during the late preconception period, first and last trimester or throughout pregnancy, and first postnatal year were higher in boys, without parental atopy, without mold/damp stains, and without window condensation.

$\mathrm{SO}_{2}$ is a highly water-soluble and irritating gas that is mainly from industrial coal and fossil fuel emissions, and could be an important cause of human respiratory diseases and serious air pollution (HaiFeng et al., 2014). $\mathrm{SO}_{2}$ can be absorbed by wet mucous membranes, generating sulfuric acid and sulfite as it passes through the respiratory tract. Exposure to high concentrations of $\mathrm{SO}_{2}$ can cause mucosal injury and a series of clinical symptoms (Abdalla 2007). However, many studies have suggested that early-life exposure to $\mathrm{SO}_{2}$, combined with other air pollutants like $\mathrm{PM}_{10}$ and $\mathrm{NO}_{2}$, can make children susceptible to URTIs (Bobak and Leon 1992; Bobak and Leon 1999; Soto-Martinez and Sly 2010). Therefore, the problem of environmental quality urgently needs our attention. Developing new energy sources and improving coalburning technology should be carried out as soon as possible.

The strengths of this study are that we investigated early-life exposure to ambient air pollution and a specific type of URTI based on a relatively large-sample cohort, and that we specifically divided early-life exposure into three timing windows to ensure the reliability and consistency of the results. However, $t$.

This study also had some limitations. First, the information obtained from questionnaires were retrospective, which may have involved recall bias. Families traveling and moving could result in exposure misclassification. Second, we calculated children's exposure based on air pollutant concentration in kindergartens but not at home or in the workplace. Third, an inverse distance weighted method was adopted for modeling the exposure to air pollution using the data obtained by the monitoring stations for ambient air quality, which might have resulted in exposure bias due to the small number of monitoring stations and the unclear air pollution source and condition for land use.

\section{CONCLUSION}

Laryngitis among preschool children was associated with late conception, prenatal (especially first and third trimesters), and early-postnatal exposure to $\mathrm{SO}_{2}$, an indicator of industrial air

\section{REFERENCES}

Abdalla, I. L. (2007). Ultrastructural Study of the Effect of Air Pollution by So2 on the Respiratory Air-Ways. Afr. J. Health Sci. 14, 129-136. doi:10.4314/ajhs. v14i3.30859

Acharya, P., Mishra, S. R., and Berg-Beckhoff, G. (2015). Solid Fuel in Kitchen and Acute Respiratory Tract Infection Among under Five Children: Evidence from nepal Demographic and Health Survey 2011. J. Community Health 40, 515-521. doi:10. 1007/s10900-014-9965-0

Aguilera, I., Pedersen, M., Garcia-Esteban, R., Ballester, F., Basterrechea, M., Esplugues, A., et al. (2012). Early-life Exposure to Outdoor Air Pollution and Respiratory Health, Ear Infections, and Eczema in Infants from the pollution. The results indicated that early-life exposure to industrial air pollution may contribute to the development of childhood laryngitis. Hence, protective measures need to be implemented to mitigate serious industrial emissions and improving ambient air quality.

\section{DATA AVAILABILITY STATEMENT}

The raw data supporting the conclusion of this article will be made available by the authors, without undue reservation.

\section{ETHICS STATEMENT}

The studies involving human participants were reviewed and approved by Shenzhen Institute of Information Technology. Written informed consent to participate in this study was provided by the participants' legal guardian/next of kin.

\section{AUTHOR CONTRIBUTIONS}

YL: Investigation, Data analysis and Writing. MD: Investigation and Writing-Reviewing and Editing. DZ: Writing-Reviewing and Editing. CL: Supervision. SL: Supervision.

\section{FUNDING}

This work was supported by Shenzhen Science and Technology Project JCYJ20180307160045548, Longgang District Science and Technology Project KJ2021D004, the National Natural Science Foundation of China 42007391, the Natural Science Foundation of Hunan Province 2021JJ30813 and the Project of Shenzhen Institute of Information Technology (SZIIT2020KJ004 and HX-227).

\section{SUPPLEMENTARY MATERIAL}

The Supplementary Material for this article can be found online at: https://www.frontiersin.org/articles/10.3389/fenvs.2022.830106/ full\#supplementary-material

Inma Study. Environ. Health Perspect. 121, 387-392. doi:10.1289/ehp. 1205281

Bobak, M., and Leon, D. A. (1992). Air Pollution and Infant Mortality in the Czech republic, 1986-88. The Lancet 340, 1010-1014. doi:10.1016/0140-6736(92) 93017-h

Bobak, M., and Leone, D. A. (1999). The Effect of Air Pollution on Infant Mortality Appears Specific for Respiratory Causes in the Postneonatal Period. Epidemiology 10, 666-670. doi:10.1097/00001648-19991100000004

Brauer, M., Hoek, G., Van Vliet, P., Meliefste, K., Fischer, P. H., Wijga, A., et al. (2002). Air Pollution from Traffic and the Development of Respiratory Infections and Asthmatic and Allergic Symptoms in Children. Am. J. Respir. Crit. Care Med. 166, 1092-1098. doi:10.1164/rccm.200108-007oc 
Çetinkaya, F., and Turgut, S. (2001). The Relation between Recurrent Acute Subglottic Laryngitis and Asthma in Children. Int. J. Pediatr. Otorhinolaryngol. 57, 41-43. doi:10.1016/s0165-5876(00)00436-5

Chauhan, A. J., and Johnston, S. L. (2003). Air Pollution and Infection in Respiratory Illness. Br. Med. Bull. 68, 95-112. doi:10.1093/bmb/ldg022

Coates, H. (2006). "Laryngitis and Pharyngitis," in Encyclopedia of Respiratory Medicine. Editor G. J. Laurent and S. D. Shapiro (Elsevier) Vol. 2, 529-534.

Deng, Q., Lu, C., Jiang, W., Zhao, J., Deng, L., and Xiang, Y. (2017a). Association of Outdoor Air Pollution and Indoor Renovation with Early Childhood Ear Infection in china. Chemosphere 169, 288-296. doi:10.1016/j.chemosphere.2016.11.079

Deng, Q., Lu, C., Li, Y., Chen, L., He, Y., Sundell, J., et al. (2017b). Association between Prenatal Exposure to Industrial Air Pollution and Onset of Early Childhood Ear Infection in china. Atmos. Environ. 157, 18-26. doi:10.1016/j. atmosenv.2017.03.005

Deng, Q., Lu, C., Norbäck, D., Bornehag, C.-G., Zhang, Y., Liu, W., et al. (2015). Early Life Exposure to Ambient Air Pollution and Childhood Asthma in china. Environ. Res. 143, 83-92. doi:10.1016/j.envres.2015.09.032

Deng, Q., Lu, C., Ou, C., Chen, L., and Yuan, H. (2016). Preconceptional, Prenatal and Postnatal Exposure to Outdoor and Indoor Environmental Factors on Allergic Diseases/symptoms in Preschool Children. Chemosphere 152, 459-467. doi:10.1016/j.chemosphere.2016.03.032

DiFranza, J. R., Aligne, C. A., and Weitzman, M. (2004). Prenatal and Postnatal Environmental Tobacco Smoke Exposure and Children's Health. Pediatrics 113, 1007-1015. doi:10.1542/peds.113.s3.1007

Elaina, M., Elaine, F., Anna, M., Ulrike, G., Claudia, K., Olena, G., et al. (2013). "Traffic-related Air Pollution and Respiratory Infections during Early Childhood: An Analysis of Seven European Birth Cohorts within the Escape Project," in Proceedings of the ISEE Conference Abstracts.

Fuentes-Leonarte, V., Estarlich, M., Ballester, F., Murcia, M., Esplugues, A., Aurrekoetxea, J. J., et al. (2015). Pre- and Postnatal Exposure to Tobacco Smoke and Respiratory Outcomes during the First Year. Indoor air 25, 4-12. doi:10.1111/ina.12128

Gascon, M., Casas, M., Morales, E., Valvi, D., Ballesteros-Gómez, A., Luque, N., et al. (2015). Prenatal Exposure to Bisphenol a and Phthalates and Childhood Respiratory Tract Infections and Allergy. J. Allergy Clin. Immunol. 135, 370-378. doi:10.1016/j.jaci.2014.09.030

Gehring, U., Cyrys, J., Sedlmeir, G., Brunekreef, B., Bellander, T., Fischer, P., et al. (2002). Traffic-related Air Pollution and Respiratory Health during the First 2 Yrs of Life. Eur. Respir. J. 19, 690-698. doi:10.1183/09031936.02.01182001

Ghosh, R., Joad, J., Benes, I., Dostal, M., Sram, R. J., and Hertz-Picciotto, I. (2012). Ambient Nitrogen Oxides Exposure and Early Childhood Respiratory Illnesses. Environ. Int. 39, 96-102. doi:10.1016/j.envint.2011.10.001

Hai-Feng, L. I., Yan, Z., Pei-gang, J., and Hong-xing, J. (2014). Risk Factors for Recurrent Respiratory Infections in Preschool Children in china. Iran J. Pediatr. 24, 14-22.

Harris, A. M., Hicks, L. A., and Qaseem, A. (2016). Appropriate Antibiotic Use for Acute Respiratory Tract Infection in Adults: Advice for High-Value Care from the American College of Physicians and the Centers for Disease Control and Prevention. Ann. Intern. Med. 164 (6), 425-434. doi:10.7326/m15-1840

Isabelle, R., Samet, J. M., Smith, K. R., and Nigel, B. (2002). Outdoor Air Pollution and Acute Respiratory Infections Among Children in Developing Countries. J. Occup. Environ. Med. 44, 640-649.

Jedrychowski, W., Galas, A., Pac, A., Flak, E., Camman, D., Rauh, V., et al. (2005). Prenatal Ambient Air Exposure to Polycyclic Aromatic Hydrocarbons and the Occurrence of Respiratory Symptoms over the First Year of Life. Eur. J. Epidemiol. 20, 775-782. doi:10.1007/s10654-005-1048-1

Kan, H., Chen, R., and Tong, S. (2012). Ambient Air Pollution, Climate Change, and Population Health in china. Environ. Int. 42, 10-19. doi:10.1016/j.envint. 2011.03 .003
Kenealy, T. (2011). Sore Throat. BMJ Clinical Evidence 2011.

Kim, D., Chen, Z., Zhou, L.-F., and Huang, S.-X. (2018). Air Pollutants and Early Origins of Respiratory Diseases. Chronic Dis. translational Med. 4, 75-94. doi:10.1016/j.cdtm.2018.03.003

Knoop, K. A., McDonald, K. G., Kulkarni, D. H., and Newberry, R. D. (2016). Antibiotics Promote Inflammation through the Translocation of Native Commensal Colonic Bacteria. Gut 65 (7), 1100-1109. doi:10.1136/gutjnl-2014-309059

Kozyrskyj, A. L., Klassen, T. P., Moffatt, M., and Harvey, K. (2010). Short-course Antibiotics for Acute Otitis media. Cochrane Database Syst. Rev.

Lu, S., Kang, L., Liao, S., Ma, S., Zhou, L., Chen, D., et al. (2018). Phthalates in PM2.5 from Shenzhen, China and Human Exposure Assessment Factored Their Bioaccessibility in Lung. Chemosphere 202, 726-732. doi:10.1016/j. chemosphere.2018.03.155

Miller, R. L., and Ho, S.-m. (2008). Environmental Epigenetics and Asthma. Am. J. Respir. Crit. Care Med. 177, 567-573. doi:10.1164/rccm.200710-1511pp

Norbäck, D., Lu, C., Zhang, Y., Li, B., Zhao, Z., Huang, C., et al. (2017). Common Cold Among Pre-school Children in China - Associations with Ambient PM 10 and Dampness, Mould, Cats, Dogs, Rats and Cockroaches in the home Environment. Environ. Int. 103, 13-22. doi:10.1016/j.envint.2017.03.015

Odo, D. B., Yang, I. A., Dey, S., Hammer, M. S., van Donkelaar, A., Martin, R. V., et al. (2022). Ambient Air Pollution and Acute Respiratory Infection in Children Aged under 5 Years Living in 35 Developing Countries. Environ. Int. 159, 107019. doi:10.1016/j.envint.2021.107019

Soto-Martinez, M., and Sly, P. D. (2010). Review Series: What Goes Around, Comes Around: Childhood Influences on Later Lung Health?: Relationship between Environmental Exposures in Children and Adult Lung Disease: The Case for Outdoor Exposures. Chron. Respir. Dis. 7, 173-186. doi:10.1177/ 1479972309345929

Watts, J. (2005). China: The Air Pollution Capital of the World. The Lancet 366, 1761-1762. doi:10.1016/s0140-6736(05)67711-2

Wood, J. M., Athanasiadis, T., and Allen, J. (2014). Laryngitis. Bmj 349, g5827. doi:10.1136/bmj.g5827

Zhang, Q., Guo, Z., Bai, Z., and MacDonald, N. E. (2013). A 4 Year Prospective Study to Determine Risk Factors for Severe Community Acquired Pneumonia in Children in Southern china. Pediatr. Pulmonol. 48, 390-397. doi:10.1002/ppul.22608

Zhang, Q., He, K., and Huo, H. (2012). Cleaning China's Air. Nature 484, 161-162. doi:10.1038/484161a

Zhou, W., Yuan, D., Ye, S., Qi, P., Fu, C., and Christiani, D. C. (2001). Health Effects of Occupational Exposures to Vehicle Emissions in Shanghai. Int. J. Occup. Environ. Health 7, 23-30. doi:10.1179/oeh.2001.7.1.23

Conflict of Interest: The authors declare that the research was conducted in the absence of any commercial or financial relationships that could be construed as a potential conflict of interest.

Publisher's Note: All claims expressed in this article are solely those of the authors and do not necessarily represent those of their affiliated organizations, or those of the publisher, the editors and the reviewers. Any product that may be evaluated in this article, or claim that may be made by its manufacturer, is not guaranteed or endorsed by the publisher.

Copyright $\odot 2022 \mathrm{Liu}$, Deng, Zhang, Lu and Lu. This is an open-access article distributed under the terms of the Creative Commons Attribution License (CC BY). The use, distribution or reproduction in other forums is permitted, provided the original author(s) and the copyright owner(s) are credited and that the original publication in this journal is cited, in accordance with accepted academic practice. No use, distribution or reproduction is permitted which does not comply with these terms. 